\title{
Relationship between Maternal Hemodynamics and Hematocrit and Hemodynamic Effects of Isovolemic Hemodilution and Hemoconcentration in the Awake Late-Pregnant Guinea Pig
}

\author{
LOUIS L. PEETERS, CARLA M. VERKESTE, PRAMOD R. SAXENA, AND \\ HENK C. S. WALLENBURG \\ Departments of Obstetrics and Gynecology, and Pharmacology, Erasmus University Medical School, 3000 DR \\ Rotterdam, The Netherlands
}

\begin{abstract}
The relationship between the spontaneous hematocrit (Hct) and maternal hemodynamics and the hemodynamic effects of experimentally induced changes in this Hct were studied in the awake late-pregnant guinea pig. In animals with a relatively low Hct, cardiac output fractions and blood flows to brain and heart determined with microspheres were higher and those to kidneys lower than in animals with a relatively high $\mathrm{Hct}$. The $\mathrm{O}_{2}$ flows to the kidneys and skin in the former animals were also lower. Cardiac output, heart rate, systemic blood pressure, and blood flows to the other organs, including the placenta, were not related to the Hct. Placental blood flow was found to vary in proportion to cardiac output. Both hemodilution and hemoconcentration induced changes in the cardiac output distribution and organ flows which resembled those observed in the spontaneous relation with Hct. In addition, hemodilution decreased systemic blood pressure. Both hemodilution and hemoconcentration increased placental blood flow; the magnitude of this flow increase was twice as high after hemodilution. The changes in oxygen flows after experimentally induced hemodilution and hemoconcentration appears to be directly related to the concomitant change in whole blood oxygen capacity. It is concluded that in the awake late-pregnant guinea pig, only brain, heart, and kidney perfusion vary in relation to the arterial Hct. The higher placental blood flow after isovolemic hemodilution may be a result of better blood rheology in the porous-like intervillous space of the placentas in a state of reduced systemic blood pressure. The modest rise in placental blood flow after isovolemic hemoconcentration appears to be mostly related to the methodology employed. (Pediatr Res 21: 584-589, 1987)
\end{abstract}

Abbreviations

Hct, hematocrit

$\mathrm{Hb}$, hemoglobin

Resp, respiration

The Hct affects both the viscosity and the oxygen-carrying capacity of circulating blood. To allow optimal $\mathrm{O}_{2}$ transport, the Hct must be such that adequate $\mathrm{O}_{2}$-carrying capacity is combined

Received September 8, 1986; accepted January 8, 1987.

Correspondence Dr. L. L. H. Peeters, Department of Obstetrics and Gynecology, Erasmus University Medical School, Room Ee 2273b, P. O. Box 1738, 3000 DR Rotterdam, The Netherlands.

Supported by the Netherlands Organization for the Advancement of Pure Research. with optimal fluidity of the blood in the microcirculation. In pregnant women, the Hct shows a fall of $15 \%$ in midgestation, mainly due to a gradual rise in plasma volume, to about $40 \%$ above nonpregnant levels (1). Pregnancies complicated by preeclampsia or intrauterine growth retardation show a certain degree of hemoconcentration which causes a relative rise in $\mathrm{Hct}$ and various plasma proteins. These alterations affect whole blood viscosity at different levels: elevated concentrations of proteins increase plasma viscosity and plasma osmolality (2). Increased plasma osmolality, in turn, diminishes red cell deformability (3). Elevated plasma concentrations of fibrinogen and certain macroglobulines enhance red cell aggregability (4). The relative contribution of these factors to the rheologic properties of blood is mainly determined by the behavior of the sheared erythrocytes within each specific microvasculature. The reduced total blood volume in preeclampsia may explain the relatively low cardiac output (5) and reduced uteroplacental blood flow (6) in this condition. The additional effect of an elevated whole blood viscosity on an already compromised uteroplacental blood flow is unknown.

In order to quantitate the relative effect on the maternal circulation of each individual blood viscosity parameter, these parameters should be manipulated selectively in an appropriate, in vivo experimental model. Previous studies involved exchange transfusions in the anesthetized animal with Hct changes beyond the normal limits of the physiologic range $(7,8)$. From data generated by these studies, it is difficult to differentiate between Hct and non-Hct related effects of isovolemic exchange transfusion within the physiologic range of Hct.

The present study was designed to evaluate the relationship between maternal cardiovascular dynamics and Hct and the effects on the maternal circulation of acute changes in Hct induced by means of isovolemic hemodilution or isovolemic hemoconcentration in the awake late-pregnant guinea pig. Inherent to this experimental design is the fact that changes in $\mathrm{O}_{2}$ content and blood viscosity will remain linked together. Consequently, Hct-related changes could either be caused by a change in $\mathrm{O}_{2}$ or by a change in blood viscosity. The guinea pig was chosen for this study because of its hemochorial placenta which may allow extrapolation to human pregnancy.

\section{MATERIALS AND METHODS}

Thirty-six albino guinea pigs with known postconceptional dates were used in this study. The animals were bred in our own laboratory facility. Details about breeding, housing, and handling are described in a previous report (9). Between day 48 and 52 of pregnancy, polyethylene catheters were inserted into the left 
ventricle and abdominal aorta using aseptic techniques $(9,10)$. Both catheters were tunnelled subcutaneously and exteriorized between the shoulder blades. They were flushed once weekly with saline. Experiments were performed at least 5 days after surgery at a gestational age between 55 and 60 days. At the time of the experiment all animals had adequately recovered from surgery, as reflected in a return to the presurgical weight gain.

Experimental protocol. In all animals the cardiac output, cardiac output distribution, and regional blood flows were determined in duplicate on 2 consecutive days. On the 1st day these variables were measured without preceding manipulation. After these so-called "control" measurements the animals were subjected to either an isovolemic hemodilution, a "sham" procedure, or an isovolemic hemoconcentration. On the next day, $24 \mathrm{~h}$ later, the second set of so-called "posttransfusion" measurements were obtained. Arterial blood pressure and heart rate were monitored throughout both periods of experimentation. The flow measurements with $15 \mu \mathrm{m}$ microspheres (NEN, Dreieich, West Germany) were performed using the reference sampling technique (10). Each blood flow measurement was based on the results of two separate microsphere injections under the same experimental condition as described in detail in a previous report (11). At the time of the injections of microspheres a reference sample of blood was withdrawn from the abdominal aorta at a constant rate of $0.65 \mathrm{ml} / \mathrm{min}$. Prior to each microsphere experiment, an arterial blood sample was obtained $(0.3 \mathrm{ml})$ for the measurement of blood gases (ABL3, Radiometer, Copenhagen, Denmark), $\mathrm{O}_{2}$ saturation, $\mathrm{Hb}$ concentration (OSM2, Radiometer), and Hct (microcapillary technique). Fifteen min after the last injection of microspheres the animals were killed with an overdose of a barbiturate. The catheter positions were checked at autopsy and all organs were dissected. In all animals, the tip of the catheter used for injection of microspheres appeared to be in satisfactory position in the left ventricle. The tip of the abdominal catheter was located between the kidneys and the aortic bifurcation.

Radioactivity in each tissue aliquot and in the reference samples was determined with a well scintillation counter adapted with a 3-inch crystal (Autogamma Scintillation Counter 5220, Packard, Delft, Holland). The data were analyzed with a set of computer programs developed for processing data generated during microsphere experiments (12). All organs and reference samples contained at least 700 microspheres.

Isovolemic exchange transfusion. After the first set of blood flow measurements the animals were divided into three groups. In a hemodilution group of 13 animals, $8 \mathrm{ml}$ of blood were exchanged for $8 \mathrm{ml}$ of plasma, obtained from a nonpregnant guinea pig and stored at $-20^{\circ} \mathrm{C}$ for a period of $1-4$ months. In a sham group of 11 animals, $8 \mathrm{ml}$ of blood were withdrawn in a heparinized syringe, gently stirred for $30 \mathrm{~min}$ at $38^{\circ} \mathrm{C}$, and reinfused into the animal. The blood removed at the time of reference sampling (approximately $5 \mathrm{ml}$ ) was not replaced to avoid possible unpredictable side-effects associated with the administration of donor blood. In a hemoconcentration group of 12 animals, $8 \mathrm{ml}$ of whole blood were exchanged for $8 \mathrm{ml}$ of washed red cells. The preparation of red cells was based on the procedure described for human blood (13). Briefly, heparinized blood of a nonpregnant guinea pig was centrifuged at $1378 \times g$ for $10 \mathrm{~min}$. The supernatant was removed and the erythrocytes were gently mixed with saline (3:2 dilution) and recentrifuged. This procedure was repeated three times. Then $8 \mathrm{ml}$ of red cells were resuspended in $1 \mathrm{ml}$ of saline at $38^{\circ} \mathrm{C}$ and exchanged. An 8-ml exchange transfusion corresponds with a total volume exchange of approximately $12 \%$. Exchange transfusion did not affect the animals' food intake and weight gain.

Data presentation and statistics. The correlations between organ flows and Hct, and between placental blood flow and systemic blood pressure, heart rate, and cardiac output, were evaluated using Spearman's nonparametric correlation test. The change in lung fraction after any manipulation is indicative for systemic shunting (14). This variable was evaluated with Spearman's nonparametric correlation in its relation to fetal weight, placental weight, Hct, and all circulatory parameters determined on the 1st day of experimentation. The paired observations on cardiac output, cardiac output fractions, organ blood flows, and organ oxygen flows within each group were evaluated with Wilcoxon's signed rank test. The organ blood and oxygen flows after hemodilution, after the sham procedure, and after hemoconcentration were compared with those calculated for animals with a relatively low, intermediate, and relatively high baseline Hct, respectively (Wilcoxon's rank sum test). In Tables 1 to 4, data are expressed as mean $\pm \mathrm{SD}$. Changes in various parameters induced by exchange transfusion were not normally distributed. Therefore, where appropriate in the text, median values for these changes are given in parentheses.

\section{RESULTS}

Baseline characteristics. Some general characteristics and baseline hemodynamic parameters of the three groups of experimental animals are listed in Table 1. Only heart rate was significantly higher in the hemodilution group. In most animals the cardiac output fraction to the lungs was about $1-2 \%$ lower on the 2 nd day of experimentation (Table 2), most likely primarily related to systemic shunting of 1 st day microspheres during the period between the two experiments. No correlation was found between the fraction of cardiac output shunted overnight and fetal weight, placental weight, gestational age, and any of the other parameters measured at the time of the first set of microspheres injections. The amount of shunting was not influenced by the type of subsequent manipulation. Part of this delayed shunting may have taken place across the placentas. If all microspheres shunted in the period between the two experiments would originate from the placentas, the value calculated for the first day placental blood flow would be underestimated by a median of $17 \%$. In three animals in each group, the amount of 1 st day microspheres shunted across the systemic circulation overnight amounted to $30 \%$ or more of the amount of 1 st day microspheres recovered from the placentas. The placental blood flows of these animals were considered unreliable and therefore excluded from the subsequent analysis.

In order to evaluate the chronic relationship between various hemodynamic parameters and baseline Hct, the baseline data of all experimental animals were used. The baseline Hct ranged from 26 to 42 vol\%. Total cardiac output, systemic blood pressure, heart rate, and nonplacental vascular resistance in baseline condition did not correlate with the Hct. The cardiac output fractions and weight-specific blood flows to brain $(\mathrm{Rsp}=-0.35$, $p<0.05)$ and myocard $(\mathrm{Rsp}=-0.34, p<0.05)$ correlated negatively, and those to the kidneys ( $\operatorname{Rsp}=+0.36, p<0.05)$ correlated positively with the baseline Hct. Placental blood flow,

Table 1. General characteristics and baseline hemodynamic variables of the three groups of late-pregnant guinea pigs (means $\pm S D$ )

\begin{tabular}{lccc}
\hline & $\begin{array}{c}\text { Hemodilution } \\
(n=13)\end{array}$ & $\begin{array}{c}\text { Sham } \\
(n=11)\end{array}$ & $\begin{array}{c}\text { Hemoconcentration } \\
(n=12)\end{array}$ \\
\hline $\begin{array}{l}\text { Gestational age (days } \\
\quad \text { postconception) }\end{array}$ & $55 \pm 3$ & $57 \pm 2$ & $57 \pm 2$ \\
Maternal wt (g) & $922 \pm 94$ & $888 \pm 146$ & $971 \pm 117$ \\
Litter size & $3.4 \pm 1.0$ & $2.7 \pm 1.1$ & $3.3 \pm 0.8$ \\
Mean fetal wt (g) & $54 \pm 14$ & $57 \pm 9$ & $55 \pm 9$ \\
Mean arterial pressure & $49 \pm 10$ & $53 \pm 10$ & $55 \pm 5$ \\
$\quad$ torr) & & & \\
Heart rate (bpm) & $327 \pm 29^{*}$ & $269 \pm 31$ & $259 \pm 34$ \\
Hematocrit (vol\%) & $34 \pm 4$ & $33 \pm 4$ & $32 \pm 4$ \\
\hline
\end{tabular}

${ }^{*} p<0.05$ (hemodilution versus two other groups, Wilcoxon rank sum test). 
Table 2. Cardiac output ( $\mathrm{ml} / \mathrm{min})$, heart rate (bpm), systemic blood pressure (torr), nonplacental vascular resistance (torr $\cdot g \cdot$ min) $\mathrm{ml})^{*}$, and cardiac output distribution (\%), before and $20 \mathrm{~h}$ after hemodilution, sham procedure (control), and hemoconcentration in the awake late-pregnant guinea pig

\begin{tabular}{|c|c|c|c|c|c|c|}
\hline & \multicolumn{2}{|c|}{ Hemodilution $(n=13)$} & \multicolumn{2}{|c|}{ Sham $(n=11)$} & \multicolumn{2}{|c|}{$\begin{array}{l}\text { Hemoconcentration } \\
\qquad(n=12)\end{array}$} \\
\hline & Before & After & Before & After & Before & After \\
\hline Hematocrit & $34 \pm 4$ & $28 \pm 4 \dagger$ & $33 \pm 4$ & $32 \pm 3 \dagger$ & $32 \pm 4$ & $38 \pm 3 \dagger$ \\
\hline Cardiac output & $232 \pm 54$ & $222 \pm 42$ & $225 \pm 36$ & $209 \pm 40 \dagger$ & $225 \pm 38$ & $223 \pm 22$ \\
\hline Heart rate & $327 \pm 29$ & $310 \pm 46 \dagger$ & $269 \pm 31$ & $265 \pm 32$ & $259 \pm 34$ & $264 \pm 37$ \\
\hline Blood pressure & $49 \pm 10$ & $43 \pm 8 \dagger$ & $53 \pm 10$ & $52 \pm 5$ & $55 \pm 5$ & $56 \pm 5$ \\
\hline \multicolumn{7}{|c|}{ Systemic vascular resistance } \\
\hline Nonplacental & $133 \pm 28$ & $120 \pm 24$ & $137 \pm 20$ & $135 \pm 13$ & $153 \pm 22$ & $162 \pm 18$ \\
\hline Placental & $30 \pm 12$ & $22 \pm 7 \dagger$ & $27 \pm 10$ & $29 \pm 7$ & $40 \pm 7$ & $40 \pm 12$ \\
\hline \multicolumn{7}{|l|}{ Cardiac output fractions } \\
\hline Lungs & $4.9 \pm 2.0$ & $3.7 \pm 1.6 \dagger$ & $5.1 \pm 1.6$ & $3.6 \pm 1.8 \dagger$ & $5.1 \pm 1.7$ & $3.8 \pm 1.1 \dagger$ \\
\hline Myocardium & $3.5 \pm 0.9$ & $4.1 \pm 1.2 \dagger$ & $3.6 \pm 1.1$ & $3.6 \pm 0.6$ & $2.9 \pm 0.6$ & $2.9 \pm 0.7$ \\
\hline Brain & $1.9 \pm 0.5$ & $2.3 \pm 0.5 \dagger$ & $2.2 \pm 0.2$ & $2.4 \pm 0.5 \dagger$ & $2.1 \pm 0.5$ & $1.9 \pm 0.5$ \\
\hline Kidneys & $10.3 \pm 1.7$ & $9.2 \pm 1.4 \dagger$ & $9.9 \pm 2.0$ & $9.3 \pm 3.0$ & $9.8 \pm 1.8$ & $10.9 \pm 2.5$ \\
\hline Gastrointestinal tract & $16.6 \pm 2.6$ & $16.7 \pm 2.1$ & $17.8 \pm 2.2$ & $17: 4 \pm 1.4$ & $17.9 \pm 4.8$ & $16.9 \pm 4.6$ \\
\hline Skin & $5.8 \pm 2.0$ & $5.9 \pm 1.8$ & $5.8 \pm 1.4$ & $6.9 \pm 1.7$ & $4.9 \pm 1.3$ & $6.0 \pm 4.2$ \\
\hline Carcass & $37.6 \pm 7.6$ & $37.6 \pm 5.8$ & $37.3 \pm 6.4$ & $38.4 \pm 6.3$ & $40.0 \pm 8.7$ & $38.0 \pm 9.1$ \\
\hline Placenta & $4.9 \pm 1.3$ & $7.0 \pm 1.3 \dagger$ & $5.4 \pm 1.2$ & $6.3 \pm 1.4$ & $4.6 \pm 1.3$ & $6.0 \pm 1.8 \dagger$ \\
\hline Placenta§ & $0.7 \pm 0.2$ & $0.9 \pm 0.3 \dagger$ & $0.7 \pm 0.2$ & $0.8 \pm 0.2$ & $0.5 \pm 0.2$ & $0.7 \pm 0.2 \dagger$ \\
\hline
\end{tabular}

* Placental vascular resistance per $\mathrm{g}$ fetal mass; nonplacental vascular resistance per $\mathrm{g}$ maternal minus fetoplacental weight.

$\dagger p<0.05$ (Wilcoxon's signed rank test).

$\ddagger$, $\S$ Placental fraction per $100 \mathrm{~g}$ of fetus and per g placenta, respectively.

which varied independently of the spontaneous Hct, did correlate with total cardiac output (Rsp $=+0.49, n=27, p<0.01)$. The oxygen flows, defined as the product of arterial oxygen content and blood flow, to the kidneys (Rsp $=+0.56, p<0.001)$ and skin $(\mathrm{Rsp}=+0.32, p<0.05)$ correlated positively with the baseline Hct.

Effect of isovolemic hemodilution and hemoconcentration. A number of cardiovascular variables, before and $20 \mathrm{~h}$ after the isovolemic hemodilution, the sham procedure, and the isovolemic hemoconcentration are listed in Table 2 . Isovolemic hemodilution and hemoconcentration changed the Hct by $6.3 \pm$ 3.0 and $5.0 \pm 3.1 \mathrm{vol} \%$, respectively. Cardiac output did not change consistently after either exchange transfusion, but dropped significantly $(-6 \%)$ in the sham group. Hemodilution induced a significant decrease in blood pressure $(-15 \%)$, heart rate $(-6 \%)$, and the cardiac output fraction to the kidneys $(-9 \%)$. The cardiac output fractions to myocardium $(+16 \%)$, brain $(+13 \%)$, and placentas $(+45 \%)$ increased significantly. The percentage change in the flows to these four organs was comparable to the ones in the fractions. The sham procedure led to a small but consistent increase in the cardiac output fraction to the brain $(+4 \%)$. Hemoconcentration induced only a significant increase in the placental fraction of cardiac output $(+23 \%)$.

The weight-specific organ oxygen flows, before and $20 \mathrm{~h}$ after the isovolemic hemodilution, the sham procedure, and the isovolemic hemoconcentration are listed in Table 3. After hemodilution the total oxygen flow $(-23 \%)$ and the weight-specific oxygen flows to the kidneys $(-17 \%)$, the gastrointestinal tract $(-17 \%)$, and the carcass $(-15 \%)$ have decreased significantly. The oxygen flow to the placentas remained essentially unchanged. The sham procedure induced a significant decrease in total oxygen flow $(-11 \%)$ and the oxygen flow to the carcass $(-11 \%)$. After hemoconcentration, total oxygen flow $(+27 \%)$ and all organ oxygen flows, except that to the brain, had increased significantly with a median value between 20 and $30 \%$. Placental oxygen flow had increased with a median value of $55 \%$.

A number of cardiovascular parameters together with the distribution of oxygen over various organs after hemodilution, sham, and hemoconcentration were compared with these parameters at corresponding spontaneous Hct. To this end, all base- line observations on oxygen flows and nonplacental vascular resistance were divided over three reference groups: an anemic group (Hct $<31$ vol\%), a normal Hct group (31 < Hct $<36$ vol\%), and a polycythemic group (Hct $>36$ vol\%) (Table 4). The placental flow and vascular resistance after hemodilution was significantly lower than in the anemic reference group. Total and renal oxygen flow were significantly lower after the sham procedure as compared to the values observed in the normal Hct reference group. Placental $\mathrm{O}_{2}$ flow was significantly higher in both the hemodilution and hemoconcentration group as compared to the anemic and polycythemic group, respectively. All other oxygen flows after hemodilution and hemoconcentration did not differ significantly from those in the anemic and polycythemic reference group, respectively.

The guinea pig is a polytocous species which allows intralitter comparisons. The weight difference between the smallest and largest littermate was about $20 \%$. The median increase in placental blood flow after hemodilution and hemoconcentration in the largest littermate was 37 and $25 \%$, respectively, as compared to 68 and $20 \%$, respectively, in the smallest littermate. After hemodilution, the oxygen flow to the placenta of both the largest and smallest littermate did not change consistently. Hemoconcentration increased the oxygen flow to the largest littermate with $61 \%$ and to the smallest littermate with $42 \%$. The relative change in blood and oxygen flow observed in the largest littermate did not differ significantly from the corresponding values determined for the smallest littermate.

\section{DISCUSSION}

The Hct values observed in this study ranged from 26 to 42 vol\%. It was thought that inducing Hct changes in this interval would not trigger complex unphysiologic responses. In the latepregnant guinea pig, Hct values below $26 \mathrm{vol} \%$ are often associated with an increased lactate output by the pregnant uterus (11). Such low Hct values did not occur in the present study. On the other hand, Hct values after hemoconcentration never exceeded the spontaneously occurring Hct of $42 \mathrm{vol} \%$, a value that may still be considered physiologic (15). The effects of isovolemic hemodilution and hemoconcentration on maternal hemody- 
Table 3. Total oxygen flow (in $\mu \mathrm{mol} / \mathrm{min}$ ) and regional oxygen flows (in $\mu \mathrm{mol} / \mathrm{min} / 100 \mathrm{~g}$ ) before and $20 \mathrm{~h}$ after hemodilution, sham procedure (control), and hemoconcentration in the awake late-pregnant guinea pig

\begin{tabular}{|c|c|c|c|c|c|c|}
\hline & \multicolumn{2}{|c|}{ Hemodilution $(n=9)$} & \multicolumn{2}{|c|}{ Sham $(n=10)$} & \multicolumn{2}{|c|}{ Hemoconcentration $(n=12)$} \\
\hline & Before & After & Before & After & Before & After \\
\hline Total $\mathrm{O}_{2}$ flow & $1678 \pm 380$ & $1155 \pm 299^{*}$ & $1561 \pm 337$ & $1321 \pm 253^{*}$ & $1384 \pm 384$ & $1644 \pm 246^{*}$ \\
\hline Myocardium & $2068 \pm 326$ & $1915 \pm 600$ & $2248 \pm 579$ & $2040 \pm 433$ & $1582 \pm 399$ & $1936 \pm 466^{*}$ \\
\hline Brain & $676 \pm 203$ & $641 \pm 191$ & $818 \pm 142$ & $788 \pm 157$ & $675 \pm 212$ & $731 \pm 183$ \\
\hline Kidneys & $2595 \pm 959$ & $1825 \pm 568^{*}$ & $2376 \pm 414$ & $2014 \pm 219$ & $1945 \pm 492$ & $2655 \pm 990^{*}$ \\
\hline Gastrointestinal tract & $971 \pm 278$ & $842 \pm 365^{*}$ & $1017 \pm 183$ & $906 \pm 82$ & $851 \pm 229$ & $998 \pm 230^{*}$ \\
\hline Skin & $69 \pm 30$ & $57 \pm 27$ & $84 \pm 11$ & $83 \pm 19$ & $60 \pm 22$ & $72 \pm 13^{*}$ \\
\hline Carcass & $172 \pm 25$ & $109 \pm 25^{*}$ & $172 \pm 42$ & $153 \pm 35^{*}$ & $145 \pm 48$ & $163 \pm 48^{*}$ \\
\hline Placenta $\uparrow$ & $899 \pm 299$ & $831 \pm 325$ & $815 \pm 206$ & $843 \pm 128$ & $641 \pm 223$ & $1033 \pm 233^{*}$ \\
\hline
\end{tabular}

${ }^{*} p<0.05$ (Wilcoxon's signed rank test).

$\dagger$ Per $\mathrm{kg}$ fetal weight.

Table 4. Blood pressure (torr), nonplacental vascular resistance (torr.g. $\mathrm{min} / \mathrm{ml}$ ), total oxygen flow ( $\mu \mathrm{mol} / \mathrm{min})$, oxygen flows to individual organs $(\mu \mathrm{mol} / \mathrm{min} / 100 \mathrm{~g})$ in a condition of chronic anemia $(n=12)$, normal $\mathrm{Hb}(n=12)$, and polycythemia $(n=11)$ as compared to the state after hemodilution $(n=9)$, after the sham procedure $(n=10)$, and after hemoconcentration $(n=12)$, respectively

\begin{tabular}{|c|c|c|c|c|c|c|}
\hline & \multicolumn{2}{|c|}{ Low Htc } & \multicolumn{2}{|c|}{ Normal Htc } & \multicolumn{2}{|c|}{ Elevated Htc } \\
\hline & $\begin{array}{c}\text { In } \\
\text { anemia }\end{array}$ & $\begin{array}{c}\text { After } \\
\text { hemodilution }\end{array}$ & $\begin{array}{c}\text { At } \\
\text { normal Ht }\end{array}$ & $\begin{array}{l}\text { After } \\
\text { Sham }\end{array}$ & $\begin{array}{c}\text { In } \\
\text { polycythemia }\end{array}$ & $\begin{array}{c}\text { After } \\
\text { Hemoconcentration }\end{array}$ \\
\hline Htc (vol\%) & $28.6 \pm 1.7$ & $28.1 \pm 3.6$ & $32.6 \pm 1.5$ & $31.8 \pm 3.1$ & $38.1 \pm 2.0$ & $38.1 \pm 3.5$ \\
\hline Systemic blood pressure & $54.9 \pm 2.3$ & $43.5 \pm 8.9 \dagger$ & $50.8 \pm 9.1$ & $51.8 \pm 5.9$ & $56.6 \pm 7.6$ & $56.3 \pm 5.4$ \\
\hline \multicolumn{7}{|l|}{ Vascular resistance } \\
\hline Nonplacental & $140 \pm 28$ & $120 \pm 24$ & $135 \pm 25$ & $135 \pm 13$ & $149 \pm 18$ & $162 \pm 18$ \\
\hline Placental & $37 \pm 16$ & $22 \pm 7 \dagger$ & $29 \pm 14$ & $29 \pm 7$ & $33 \pm 6$ & $40 \pm 12$ \\
\hline \multicolumn{7}{|l|}{$\mathrm{O}_{2}$ flows } \\
\hline Total & $1198 \pm 194$ & $1155 \pm 299$ & $1617 \pm 315$ & $1321 \pm 253 \dagger$ & $1600 \pm 358$ & $1644 \pm 246$ \\
\hline \multicolumn{7}{|l|}{ Organs } \\
\hline Myocardium & $1836 \pm 378$ & $1915 \pm 600$ & $1960 \pm 651$ & $2040 \pm 433$ & $1993 \pm 519$ & $1936 \pm 466$ \\
\hline Brain & $701 \pm 183$ & $641 \pm 191$ & $771 \pm 182$ & $788 \pm 157$ & $751 \pm 232$ & $731 \pm 183$ \\
\hline Kidneys & $1709 \pm 337$ & $1825 \pm 568$ & $2527 \pm 692$ & $2014 \pm 219 \dagger$ & $2838 \pm 834$ & $2475 \pm 483$ \\
\hline Gastrointestinal tract & $893 \pm 281$ & $842 \pm 365$ & $1001 \pm 198$ & $906 \pm 82$ & $1035 \pm 315$ & $961 \pm 116$ \\
\hline Skin & $57 \pm 23$ & $57 \pm 27$ & $81 \pm 23$ & $83 \pm 19$ & $77 \pm 25$ & $72 \pm 13$ \\
\hline Carcass & $134 \pm 48$ & $109 \pm 25$ & $164 \pm 37$ & $153 \pm 35$ & $185 \pm 55$ & $163 \pm 48$ \\
\hline Placentał̦ & $558 \pm 117$ & $831 \pm 325 \dagger$ & $838 \pm 244$ & $772 \pm 153$ & $775 \pm 270$ & $1033 \pm 233 \dagger$ \\
\hline
\end{tabular}

* Placental vascular resistance per $\mathrm{g}$ fetal mass; nonplacental vascular resistance per $\mathrm{g}$ maternal minus fetoplacental weight.

$\dagger p<0.05$ (Wilcoxon rank sum test).

$\ddagger$ Expressed per $\mathrm{kg}$ of fetal weight.

namics may be caused by the change in whole blood oxygen capacity or the change in whole blood viscosity; both variables were closely linked to one another in our experimental design. Hemodynamic changes after exchange transfusion not observed spontaneously in relation to Hct are caused by factors other than the induced Hct change, such as changes in vascular tone, hormone levels, plasma osmolality, non-Hct related viscosity, blood volume, etc. In the present study, the Hct was measured in the abdominal aorta. At the tissue level, this Hct can differ markedly from this central Hct (16). Therefore, differences in the relationship between spontaneous arterial Hct and hemodynamics, and those after hemodilution or hemoconcentration, may result from differences created in the Hct at the tissue level. Whether the injection of microspheres could have caused the observed non-Hct-related changes in the maternal circulation is highly unlikely since the microspheres circulate only briefly after intraventricular injection while the interval between the two experiments was relatively long.

Cardiac output did not correlate with the spontaneous Hct or change in response to exchange transfusion. The approximately $6 \%$ lower cardiac output after the sham procedure is most likely related to the $\pm 7 \%$ reduction in blood volume caused by blood sampling on the 1st day of experimentation. In contrast with the exchanged animals, the autotransfusion in the sham procedure did not compensate for the blood removed during the control experiment. In order to avoid more or less unpredictable changes related to (donor) blood transfusion in this group, we accepted the potential effects of slight hypovolemia: reduction in cardiac output and a shift of fluid from the interstitium into the intravascular compartment. Placental blood flow was found to vary in proportion to cardiac output. Therefore, the observed fall in cardiac output might have induced a fall in placental blood flow or might have limited a possible increase in placental blood flow after the sham procedure. In most animal species, cardiac output increases after isovolemic hemodilution (17-19). This increase is thought to be caused by a reduction in red cell aggregability which lowers the venous resistance and thus increases cardiac preload $(20,21)$. Cardiac output in guinea pig pregnancy increases only little, if any $(10,22)$. In this respect it is interesting that the fall in peripheral resistance induced with hemodilution is only associated with a fall in blood pressure without any increase in cardiac output. The following two characteristics of guinea pig pregnancy may explain this response. l) In the last 2 wk of pregnancy the guinea pig appears to develop a state of relative hypovolemia because of a gradually developing gap between the rate of plasma volume expansion and the growth rate of the uteroplacental vascular bed. Support for this comes from recent experiments in our laboratory where hypervolemic 
hemodilution was found to induce a significant rise in cardiac output and a suppression of the normal redistribution of cardiac output in late pregnancy (10). 2) We found that red cell aggregability in the guinea pig also measured with a Myrenne MA1 apparatus was about one-third the value reported for the human (4). In addition, shear rate is likely to be several fold higher in the guinea pig than for example in the human because of its relatively high cardiac output $(10,21)$. Because of these two factors, changes in low shear viscosity play a negligible role in the guinea pig. Therefore, hemodilution will only decrease highshear viscosity which implies no reduction in venous resistance and thus also no increase in cardiac preload.

It is noteworthy that in the present study placental blood flow increased approximately 25 and $45 \%$ after isovolemic hemodilution and hemoconcentration, respectively. Assuming normal fetal growth and placental blood flow increasing in proportion to fetal size $(10,22), \pm 7 \%$ of this increase in both groups can be accounted for by the advancement of the pregnancy between the two experiments. This increase was probably blunted in the sham group due to the reduction in blood volume. Overnight systemic shunting did not correlate with any of the hemodynamic variables measured. Therefore, it is likely that this shunting is similar in the three experimental groups. Assuming also comparable overnight leakage of microspheres from the placentas in the three groups, most of the increase in the placental fraction of cardiac output in the sham group (median $=16 \%$ ) may be considered a result of shunting. Subtraction of both "flow-increasing" factors $(20-25 \%)$ would result in a net procedure-related increase in placental blood flow after hemodilution of $\pm 20 \%$. The observed increase in placental flow after hemoconcentration would be completely caused by advancing gestation and selective shunting.

The flow rise in the placentas in combination with the fall in peripheral vascular resistance after hemodilution may result from a reduction in whole blood viscosity. Since placental vascular resistance is not lower in anemia (Table 4), the placental circulatory response to hemodilution is caused by the hemodilution procedure itself rather than by the change in Hct. Isotonic plasma does not influence red cell deformability in vitro (3). Thus, it is unlikely that the administration of $8 \mathrm{ml}$ of isotonic donor plasma increases red cell deformability (3). It has already been mentioned that the role of changes in red cell aggregability is probably negligible in the guinea pig. Therefore, it seems that the increase in placental perfusion after hemodilution cannot be attributed to a change in these viscosity variables. In the present study, blood volume was not determined. Therefore, it cannot be excluded that the increase in placental perfusion is somehow related to an increase in circulating blood volume, e.g. due to a transfusion-related change in plasma osmolality. The absence of a rise in cardiac output makes any important change in blood volume unlikely. The hemochorial placental has a unique microarchitecture consisting of a porous structure instead of a capillary bed (23). In a capillary bed a rise in pressure gradient increases shear rate which in turn, reduces apparent viscosity $(3$, 24). In contrast, a rise in pressure gradient and thus shear rate across a porous structure, is known to cause an increase in apparent viscosity (25).

To explain the selective, non-Hct-related rise in placental perfusion the following hypothesis is proposed. The fall in Hct after hemodilution decreases high-shear viscosity and thus peripheral vascular resistance. The associated lower blood pressure and thus perfusing pressure across the systemic circulation has a favorable mechanical effect selectively on the placental microcirculation. Blood rheology in the intervillous space improves in response to the lower shear rate giving rise to a decrease of the apparent viscosity across the placentas relative to the other capillary beds. The flow rise in the placentas, however, lasts only for the period during which the blood pressure is reduced. It is likely that baroreceptor and chemoreceptor responses will gradually normalize blood pressure and thus indirectly normalize the elevated placental blood flow. Placental oxygen flow is to de- crease gradually to the reduced value observed in anemic animals (Table 4). It should be stressed that this hypothesis is not based on experimental data. In fact, it is yet unknown how the pressureflow relationship across a hemochorial placenta exists in an intact animal, where the simultaneously determined pressure-flow relationship of other organs can serve as a reference. The guinea pig placenta extracts about $60 \%$ of the supplied oxygen due to its unique countercurrent vascular arrangement $(9,29)$. Therefore, it is unlikely that improvement of rheologic properties of blood within the intervillous space, associated with a fall in oxygen capacity, will improve transplacental oxygen transport. This is evidenced by the fact that a Hct of less than $27 \mathrm{vol} \%$ is associated with an increased risk for inadequate oxygenation of the conceptus in this species (11).

Taking into account the contributions of advancing gestation and overnight shunting, hemoconcentration was not followed by a significant change in placental perfusion. However, the lack of a real increase in placental perfusion after hemoconcentration further supports the absence of a relationship between placental blood flow and Hct.

Our observations of a lack of a relationship between Hct and placental blood flow are in contrast with reports on the inverse relationship between newborn weight and maternal $\mathrm{Hb}$ concentration $(26,27)$. Placental blood flow correlates closely with cardiac output which, inturn varies as a function of blood volume (19). However, in these studies no information was available on total maternal blood volume. Therefore, it is possible that the reported relationship reflects the well-known correlation between newborn weight and total plasma compartment (28). It should also be kept in mind that the animals in the present study were healthy and had normal placentas, which may not be so in women with impaired fetal growth.

A relationship between the perfusion of brain, heart, kidneys and Hct, was seen spontaneously as well as after exchange transfusion. Consequently, these changes are related to the Hct change. Hct-related changes in the perfusion of the brain and heart may reflect the relationship between flow and arterial oxygen content, as it is well known for these organs $(30-32)$. The higher blood flows to brain and heart, both after hemodilution and in a state of anemia, allow for a maintained oxygen flow to these tissues. The lower renal blood flow at reduced Hct is probably a reflex-mediated effect due to the reduced blood oxygen capacity in a state of anemia and after hemodilution. Mild anemic hypoxia enhances sympathetic activity $(31,33,34)$ which is associated with renal vasoconstriction. Hemoconcentration tended to change the cardiac output fractions to heart, brain, and kidneys in the opposite direction to what was observed after hemodilution (Table 2). In the upper range of the Hct, changes in flow are probably smaller in response to a certain change in Hct or oxygen content due to the reciprocal relationship between flow and oxygen $(30,32)$. This may explain why flow changes to brain and heart were insignificant after hemoconcentration. Hemoconcentration induces only minor changes in the maternal circulation. Nevertheless, $\mathrm{O}_{2}$ capacity of blood has increased with as much as $20 \%$, the extra oxygen being evenly distributed over the peripheral tissues. This apparently favorable effect of isovolemic hemoconcentration is probably species related since the guinea pig with its low red cell aggregability and its high blood velocity will not respond to the Hct rise with a higher venous resistance and associated lower cardiac output. Skin flow varies independently from the Hct. Therefore, the correlation between the skin oxygen supply and spontaneous Hct seems to reflect entirely the relationship between arterial oxygen capacity and Hct.

The observations on the intralitter comparison are interesting. As with Myers et al. (35), we observed in our animals about $20 \%$ lower weight-specific uteroplacental blood flow to the smallest fetus in the litter compared to the largest. In order to completely compensate for the relative underperfusion, the oxygen extraction should be as high as $\pm 72 \%$. The smallest fetus is particularly 
prone to asphyxia because its probably marginal $\mathrm{O}_{2}$ supply relies heavily on extraction. This growth-retarded fetus will be particularly vulnerable in short-term reductions in placental blood flow; e.g. as may occur during stress. Short-term episodes of mild hypoxia will also interfere with fetal growth. It follows that the smallest littermate benefits most from any rise in $\mathrm{O}_{2}$ supply because it diminishes its dependence on $\mathrm{O}_{2}$ extraction out of the danger zone.

\section{REFERENCES}

1. Hytten FE, Paintin DB 1965 Increase in plasma volume during normal pregnancy. J Obstet Gynaecol Br Commonwealth 70:402-407

2. Buchan P 1982 Pre-eclampsia. A hyperviscosity syndrome. Am J Obstet Gynecol 142:111-112

3. Chien S 1975 Biophysical behavior of the red cell in suspension. In: Surginor $\mathrm{D}$ (ed) The Red Blood Cell. Academic Press, New York, pp 1031-1033

4. Schmid-Schönbein H 1976 Microrheology of erythrocytes, blood viscosity and the distribution of blood flow in the microcirculation. In: Guyton AC, Cowley AW (eds) International Review of Physiology II, Vol 9. University Park Press, Baltimore, pp 1-62

5. Groenendijk R, Trimbos JBMJ, Wallenburg HCS 1984 Hemodynamic measurements in pre-eclampsia: Preliminary observations. Am J Obstet Gynecol 150:232-236

6. Kaar K Jouppila J, Luotola H, Toivanen J, Rekonen A 1980 Intervillous blood flow in normal and complicated late pregnancy measured by means of an intervillous ${ }^{133} \mathrm{Xe}$ method. Acta Obstet Gynecol Scand 59:7-10

7. Fumia FD, Edelstone DI, Holzman IR 1984 Blood flow and oxygen delivery to fetal organs as a function of fetal hematocrit. Am $\mathbf{J}$ Obstet Gynecol 150:274-282

8. Kiyohara Y, Masatoshi F, Takao I, Tamaki K, Seizo S, Teruo O 1985 Effects of hematocrit on brain metabolism in experimentally induced cerebral ischemia in spontaneously hypertensive rats (SHR). Stroke 16:835-840

9. Peeters LLH, Mårtensson L, van Kreel BK, Wallenburg HCS 1984 Uterine arterial and venous concentration of glucose, lactate, ketones, free fatty acids, and oxygen in the awake pregnant guinea pig. Pediatr Res 18:1172-1175

10. Peeters LLH, Grutters G, Martin CB 1980 The distribution of cardiac output in the unstressed pregnant guinea pig. Am J Obstet Gynecol 138:1177-1184

11. Peeters LLH, Mårtensson L, v KreeI BK, Saxena PR, Wallenburg HCS 1986 Movement of oxygen, glucose, and lactate across the uterus of the awake near-term guinea pig. Pediatr Res 20:730-734

12. Saxena PR, Schamhardt HC, Forsyth RP, Loeve J 1980 Computer programs for the radioactive microsphere technique. Determination of regional blood flows and other hemodynamic variables in different experimental conditions. Comp Prog Biomed 12:63-84

13. Widmann FK 1985 Technicomanual of the American Association of Blood Banks, 9th ed. Karger, Basel, Switzerland

14. Saxena PR, Verdouw PD 1982 Redistribution by 5-hydroxytryptamine of carotid arterial blood at the expense of arteriovenous anastomotic blood flow. J Physiol (Lond) 332:501-520

15. Baumann R, Bauer C, Bartels H 1971 Influence of chronic and acute hypoxia on oxygen affinity and RBC 2,3-diphosphoglycerate of rats and guinea pigs. Respir Physiol 11:135-144

16. Gaehtgens P 1980 Flow of blood through narrow capillaries: Rheological mechanisms determining capillary hematocrit and apparent viscosity. Biorheology 17:183-189

17. Sunder-Plassmann L, Kessler M, Jesch F, Dieterle R, Messmer K, 1975 Acute normovolemic hemodilution. In: Messmer $K$, Schmid-Schonbein $H$ (eds) International hemodilution Biblthca Haemat 41. Karger, Basel, Switzerland, pp 44-53

18. Messmer K 1981 Compensatory mechanism for acute dilutional anemia. Bibl Haematologica 47:31-42

19. Guyton AC, Jones CE, Colemon TG 1985 Circulatory Physiology: Cardiac Output and Its Regulation. WB Saunders, Philadelphia

20. Schmid-Schönbein H 1981 Factors promoting and preventing the fluidity of blood. In: Effros RM, Schmid-Schonbein H, Ditzel J (eds) Microcirculation. Academic Press, New York, pp 249-266

21. Messmer K, Sunder-Plassmann L, Klovekorn WP, Holper K 1972 Circulatory significance of hemodilution: rheological changes and limitations. In: Advances in Microcirculation, Vol 4. Karger, Basel Switzerland, pp 1-73

22. Myers SA, Hsui-Yu Tseng MS 1985 A longitudinal study of cardiac output in unstressed pregnant guinea pigs. Am J Physiol 248:R698-R701

23. Ramsey EM, Donner MW 1980 Placental Vasculature and Circulation. WB Saunders, Philadelphia

24. Gaehtgens P 1981 Distribution of flow and red cell flux in the microcirculation. Scand J Clin Invest 41 (suppl 156):83-87

25. Dullien FAL 1979 Porous Media, Fluid Transport and Pore Structure. Academic Press, New York

26. Mau G 1977 Hemoglobin changes during pregnancy and growth disturbances in the neonate. J Perinatol Med 5:172-177

27. Sagen N, Nilsen ST, Kim HC, Bergsjo P, Koller O 1984 Maternal hemoglobin concentration is closely related to birth weight in normal pregnancies. Acta Obstet Gynecol Scand 63:245-248

28. Goodlin RC, Quaife MA, Dirksen JW 1981 The significance, diagnosis and treatment of maternal hypovolemia as associated with fetal/maternal illness. Semin Perinatol 5:163-174

29. Meschia G 1983 Circulation to female reproductive organs. In: Geiger SR (ed) Handbook of Physiology, The Cardiovascular System III. American Physiology Society, Bethesda, MD, pp 241-269

30. Guyton AC 1976 Textbook of Medical Physiology. WB Saunders, Philadelphia

31. Fan Foun-Chung, Chen RYZ, Schuessler GB, Chien S 1980 Effects of hematocrit variation on regional hemodynamics and oxygen transport in the dog. Am J Physiol 238:H545-552

32. Brown MM, Marshall J 1985 Regulation of cerebral blood flow in response to changes in blood viscosity. Lancet 1:604-609

33. Glick G, Plauth WH Jr, Braunwald E 1964 Role of autonomic nervous system in the circulatory response to acutely induced anemia in unanesthetized dogs. J Clin Invest 43:2112-2124

34. McDonald KM 1974 Effect of hematocrit and colloid-induced changes in blood viscosity on renal hemodynamics and renin release in the dog. Circ Res 34:112-122

35. Myers SA, Sparks JW, Makowski EL, Meschia G, Battaglia FC 1982 Relationship between placental blood flow and placental and fetal size in guinea pig. Am J Physiol 243:H404-H409 